\title{
Análise das resoluções do Conselho Municipal de Saúde de Belo Horizonte no período de 1991 a 2010
}

\author{
Analysis of the resolutions of Belo Horizonte's Municipal Health \\ Council between 1991-2010
}

Janine de Azevedo Machado ${ }^{1}$

Simone Dutra Lucas ${ }^{2}$

${ }^{1}$ Prefeitura Municipal de Belo Horizonte. Av. Afonso Pena 1212, Centro. 30.130-908 Belo Horizonte MG.

jambh@ig.com.br ${ }^{2}$ Faculdade de Odontologia, Universidade Federal de Minas Gerais.

\begin{abstract}
The scope of this study is to observe how the relationship between participative and representative democracy in Belo Horizonte's Municipal Health Council (Conselho Municipal de Saúde de Belo Horizonte-CMS/BH) has been developing since its foundation in 1991 through to 2010. The methodology applied involved the analysis of approvals and vetoes from the Executive power regarding the council's resolutions, with special emphasis on the period between 1997 and 2008. The data were collected from the Resolutions Archive and from the CMS/BH webpage. The results were related to each mayor's term and to the segment of the council's presidents. The results show that only one resolution was vetoed by the Executive power, however 26\% of the resolutions do not show any record of ratification, whereby $41 \%$ of these faced opposition from the authorities in the voting process. It is hoped that the reality presented may lead to reflections regarding the exercise of power, encouraging the council members to effectively build participative democracy in this space.
\end{abstract}

Key words Participative Democracy, Municipal Health Council, Resolutions
Resumo O objetivo deste estudo é observar como vem se dando a relação entre a democracia participativa e representativa no Conselho Municipal de Saúde de Belo Horizonte (CMS/BH) desde a sua fundação em 1991 até 2010. A metodologia utilizada foi a análise das homologações e vetos do Executivo sobre as resoluções do conselho, com um aprofundamento no período entre 1997 e 2008. Os dados foram coletados no Arquivo de Resoluções e no site do CMS/BH. Os resultados foram relacionados ao mandato dos prefeitos e ao segmento dos presidentes do conselho. Os resultados demonstram que apenas uma resolução foi vetada pelo Executivo, mas 26\% não apresentam registro de homologação, sendo que $41 \%$ destas apresentaram oposição dos gestores na votação. Espera-se que a realidade apresentada possa nos levar a reflexões quanto às práticas de poder, encorajando os conselheiros para a construção efetiva da democracia participativa neste espaço.

Palavras-chave Democracia participativa, Conselho Municipal de Saúde, Resoluções 


\section{Introdução}

A participação popular é um componente fundamental no processo de redemocratização recente experimentado pelo Brasil. Em meio aos intensos debates pautados nesse período foram introduzidas ideias relacionadas ao controle das políticas públicas por parte da sociedade, à autonomia da sociedade civil nas decisões relativas aos serviços de saúde e à criação de espaços políticos institucionais caracterizados pela prática da democracia participativa - os Conselhos de Políticas Públicas. No campo da saúde esses espaços se consolidaram de modo a propiciar um campo fértil para o aprendizado prático da democracia participativa pela sociedade.

É necessário destacar a importância do Conselho Municipal de Saúde de Belo Horizonte como espaço de exercício da democracia participativa na cidade. No entanto há o risco de que sua natureza participativa venha ocorrendo em detrimento de sua função deliberativa já que resoluções ali aprovadas não vêm sendo homologadas pelo Executivo Municipal. Segundo a Lei $8.142^{1}$ as decisões deste plenário "serão homologadas pelo chefe do poder legalmente constituído em cada esfera de governo". Também a Resolução n $333^{2}$ orienta que a homologação das resoluções pelo chefe do Poder Executivo local será obrigatória, podendo o Conselho inclusive recorrer ao Ministério Público para validá-las quando não há justificativa do Executivo para alteração ou veto.

Ações contínuas e cotidianas sem momentos de análise carregam em si esterilidade e alienação. Ao descobri-las do véu do cotidiano temos a oportunidade de compreender o que não foi percebido na práxis. Assim também o é com o exercício prático da democracia participativa, essa nova possibilidade de organização política do Estado brasileiro. A tentativa de desvendar dúvidas e incertezas nesse universo se apresenta como um instigante objetivo.

O objetivo principal deste estudo foi identificar a proporção de resoluções do Conselho $\mathrm{Mu}$ nicipal de Saúde de Belo Horizonte aprovadas em plenário que recebeu veto dos prefeitos. Ao realizar o levantamento destes dados observou-se que $74 \%$ das resoluções aprovadas foram homologadas. No entanto $26 \%$ se encontravam em branco, sem o carimbo e a assinatura dos prefeitos, gerando dúvidas quanto à sua homologação ou veto. Diante da existência de um número significativo de resoluções que não foram homologadas nem vetadas novas questões se apresentaram configurando os seguintes objetivos específicos: a) analisar a quais temas se referem as resoluções não homologadas nem vetadas;

b) perceber se há alguma natureza similar entre as resoluções que não foram homologadas nem vetadas;

c) compreender quais foram os períodos de maior enfrentamento entre o poder Executivo e o Conselho de Saúde;

d) observar como vem se dando a relação entre a democracia representativa e participativa neste fórum da cidade.

\section{Métodos}

O presente estudo foi realizado tendo como fontes o site e o arquivo de Resoluções do Conselho Municipal de Saúde de Belo Horizonte. A Secretaria Executiva deste órgão organiza as resoluções em pastas seguindo a ordem cronológica de aprovação das mesmas e disponibiliza os temas das resoluções e as atas das reuniões em seu site. As resoluções homologadas pelos prefeitos apresentam o carimbo e a assinatura dos mesmos. Algumas apresentam em anexo o xerox de sua publicação no Diário Oficial do Município - DOM.

Segundo a Secretaria Executiva do CMS/BH quando uma resolução é aprovada em plenário são enviadas duas cópias da mesma para o Gabinete do Prefeito. A proposta é que uma das cópias retorne ao $\mathrm{CMS} / \mathrm{BH}$ com a assinatura de homologação. No entanto consultas informais a membros da Secretaria Executiva revelaram que algumas deliberações sem registro de homologação podem ter sido homologadas e até publicadas no DOM, mas não retornaram ao CMS/ $\mathrm{BH}$. No início do estudo surgiu a hipótese de que se pudesse conferir no DOM as resoluções publicadas a fim de se constatar com certeza quais foram realmente homologadas. Mas as dificuldades de se prever a data de publicação de cada uma e o tempo restrito de estudo inviabilizou tal análise.

Para a realização da investigação proposta foi criado um banco de dados contendo as seguintes informações:

a) Data da Resolução;

b) Número da Resolução;

c) Prefeito de Belo Horizonte em exercício;

d) Segmento do Presidente do CMS/BH em exercício;

e) Tema da Resolução sem registro.

Ao iniciar este trabalho de classificação, no entanto, diferentes aspectos se apresentaram. Entre 1989 e 1996, primeiros anos de funcionamen- 
to, o CMS/BH apresenta um volume muito pequeno de resoluções. Além disso, ainda não havia neste período uma estrutura organizada da Secretaria Executiva do CMS/BH que proporcionasse o acompanhamento do retorno das homologações aprovadas pelo Executivo. Outra questão é que o fato do mandato do atual prefeito Márcio Lacerda ainda estar em andamento impossibilitaria uma análise mais conclusiva em relação a este momento.

Assim foram coletados os dados "Data da Resolução" "Número da Resolução" "Prefeito de Belo Horizonte" e "Presidente do CMS/BH" desde a primeira resolução até a última aprovada em 2010 (dois primeiros anos do mandato Lacerda). Já os dados relativos ao "Tema da Resolução sem Registro" foram estudados através da análise documental das atas referentes ao período de 1997 a 2008. Observa-se uma pequena atividade deliberativa do CMS/BH no início de suas atividades, motivo pelo qual optou-se por detalhar melhor o intervalo 1997-2008.

Para a análise do período 1997-2008 foi necessária uma análise documental das atas relativas às plenárias que aprovaram as respectivas resoluções sem registro, a fim de que se pudesse compreender o teor da discussão e se tais votações apresentaram debates conflituosos ou não. Desta forma pode-se identificar quais resoluções sem registro de homologação pelos prefeitos coincidem com a oposição dos gestores em relação ao tema da resolução aprovada. As resoluções foram classificadas como:

Classificação 1 - temas que apresentaram oposição por parte dos gestores;

Classificação 2 - temas que não apresentaram oposição por parte dos gestores, mas que apresentam alta ou relativa possibilidade de discordância por parte da gestão;

Classificação 3 - temas que não apresentaram oposição por parte dos gestores, e que apresentam baixa ou nenhuma possibilidade de discordância por parte da gestão.

A diferenciação entre as classificações dois e três se fez necessária, pois há deliberações que confrontam a gestão, mas nas plenárias não há nenhuma oposição verbalizada por este segmento. Por exemplo, no caso das auditorias. Como poderiam os gestores se posicionar contra uma proposta de auditoria? A simples verbalização de tal oposição já levaria a dúvidas maiores. Outros temas delicados neste campo são a terceirização e os concursos públicos. Como defender uma posição contrária ao texto constitucional? Assim a classificação proposta pode revelar semelhan- ças e diferenças nos posicionamentos da gestão quanto ao teor de cada resolução, ajudando a esclarecer algumas hipóteses estudadas.

Em relação à metodologia é ainda necessário esclarecer que minha presença no Conselho Municipal de Saúde de Belo Horizonte como conselheira no segmento dos trabalhadores durante dois períodos possibilitou uma observação participante, ou seja, neste contexto a pesquisadora se coloca também como ex-membro do fórum pesquisado.

\section{Revisão de literatura}

A Constituição Federal de $1988^{3}$ introduziu a participação da comunidade nos serviços públicos de saúde. Legislações posteriores ${ }^{4}$ institucionalizaram os conselhos de saúde enquanto espaços deliberativos. Alguns estudos relacionados a essa nova realidade na democracia brasileira tem surgido, mas ainda são poucos, o que nos encoraja:

as estatísticas sobre os principais institutos de participação popular são precárias [...] e [...] praticamente inexistem estudos sobre o caráter e o papel da sociedade civil e do Estado nos conselhos de políticas públicas, relacionando o formato de suas representações com o contencioso sobre a democracia representativa ${ }^{5}$.

Segundo um estudioso da democracia cabe aos eleitores apenas "produzir um governo, ou melhor, um corpo intermediário que por sua vez produzirá um governo", sob a argumentação de que a ação coletiva é irracional e os indivíduos altamente manipuláveis. Sua defesa em favor da democracia representativa é que somente as elites políticas seriam capazes de preservar os valores centrais da democracia e colocar limites aos interesses particularistas ${ }^{6}$.

Outro estudioso se opõe a tal visão demonstrando como a experiência do Orçamento Participativo estabelece limites ao particularismo na alocação de recursos públicos. Analisando a efetividade dos desenhos participativos ele observa que desenhos de partilha de poder, nos quais se enquadram os conselhos de saúde, apresentam inclusive uma dependência menor do sistema político que os desenhos participativos "de baixo para cima” como o Orçamento Participativo, pois a sociedade civil pode se utilizar de sanções à sociedade política naqueles espaços ${ }^{7}$.

Um estudioso defende a hegemonia do Estado nos conselhos sob o seguinte argumento:

... a representação - e a representatividade decorrente do sufrágio universal, confere ao manda- 
tário, eleito após um debate com a população em torno de um programa de governo, a autorização $e$, mais que isto, a obrigação ética de implementá-lo. Isto ocorre através da efetivação de políticas públicas. Caso, juridicamente, as normas que disciplinam a representação política da sociedade na formulação dessas políticas não lhe garanta representação majoritária nos conselhos gestores - ou paritária, nos termos acima propostos - corre o Executivo o risco de ser obrigado a levar a cabo políticas, em tese, até mesmo contrárias às que foram aprovadas pela população, no debate eleitoral.

Este mesmo autor afirma que:

... uma minoria de 'iluminados', com representatividade mais do que duvidosa para a empreitada, governaria em lugar dos mandatários eleitos pela população. Ou então, prevalecendo o desacordo, a impossibilidade de resolvê-lo poderia conduzir ao eventual engessamento da administração. Tal situação só não tem ocorrido plenamente, com muita frequência, porque a administração 'dribla' as decisões dos Conselhos, ou simplesmente as descumpre $e^{5}$.

O interesse passa a ser público quando é identificado como interesse majoritário de um grupo ou uma comunidade em que haja a participação de componentes diversos da mesma ${ }^{8}$. Os conselhos de políticas públicas enquanto espaços de participação da sociedade civil e gestores são locais aonde o interesse público pode ser construído.

O mesmo autor questiona ${ }^{8}$ :

Que relação de poder o Estado quis estabelecer com a inclusão da participação popular na gestão da coisa pública?

O que quis o legislador quando possibilitou juridicamente a participação popular na decisão dos governantes?

E conclui que uma conformação da democracia que tenha como base a participação dos cidadãos nas decisões do governo é fundamental na garantia de um Estado de Direito, e ao se estruturar um Estado Democrático as democracias representativa e participativa não se excluem ou concorrem, mas são compatíveis e complementares.

De acordo com o Relatório Crítico do I Seminário Nacional de Controle Social ${ }^{9}$ os conselhos de políticas públicas surgem a partir de constatações de que a democracia representativa é insuficiente para dar voz e defender os interesses dos cidadãos e que, portanto, se faz necessária a superação do exercício de poder tradicional centralizado, patrimonialista e clientelista.

Estudos realizados nos sistemas de participação cívica na Itália constataram, assim como Toqueville, que o governo se fortalece diante de uma sociedade civil vigorosa, pois a ação coletiva dos cidadãos em busca de serviços públicos de mais qualidade promove os valores democráticos dos políticos e dos cidadãos e estabelece uma relação de cooperação indutora do capital social ${ }^{10}$ :

Assim como outras formas de capital, o capital social é produtivo, possibilitando a realização de certos objetivos que seriam inalcançáveis se ele não existisse [...]. Por exemplo, um grupo cujos membros demonstrem confiabilidade e que depositem confiança uns nos outros é capaz de realizar muito mais do que outro grupo que careça de confiabilidade ...

A reconstrução do conceito de democracia a partir de um paradigma social emancipatório é defendida, pois os processos participativos não levam a um rompimento com as instituições, mas a novas reconfigurações possíveis. Esses espaços políticos seriam fundamentais para o exercício de uma pedagogia do poder e do conflito, pois não existe exercício do poder sem emergência de conflitos, e contradições são importantes na promoção de análises e reflexões ${ }^{11}$.

Não é possível expandir capacidades por decreto ou com a participação apenas de minorias hierarquicamente superiores. Expandir capacidades exige o envolvimento e a participação efetiva na criação de projetos, e a participação social é fundamental neste sentido.

Já para outro autor ${ }^{5}$ :

os conselhos municipais não influenciam na elaboração das políticas sociais e, regra geral, foram aparelhados e cooptados pelos prefeitos.

Em outro trabalho os autores demonstram que nas cidades onde há maior participação o atendimento às demandas sociais é mais contemplado. Outra importante conclusão deste estudo é que em conselhos nos quais há maior participação de usuários, como nos de saúde, são observadas melhorias no desempenho das políticas públicas ${ }^{12}$.

O Relatório Crítico do I Seminário Nacional de Controle Social ${ }^{9}$ nos apresenta importantes reflexões:

a) é fundamental que o Controle Social se consolide e materialize através de procedimentos, rituais, regras e processos, a fim de garantir que a administração atenda aos interesses públicos;

b) as deliberações dos conselhos necessitam mesmo de homologação dos prefeitos, e há real necessidade de recorrer ao Ministério Público para que o estado acate as decisões dos conselhos, ou que o Legislativo transforme tais decisões em leis?

O Relatório propõe que os conselhos se utilizem de estratégias para fazer valer suas delibera- 
ções, como uma maior articulação com a opinião pública e movimentos de pressão no processo eleitoral.

Estudiosos realizaram uma pesquisa no CMS/ $\mathrm{BH}^{12}$ utilizando entrevistas e também a leitura das atas do período 1997-2004 e observaram a capacidade do conselho em se constituir como um fórum de deliberação. A pesquisa demonstra que $32,9 \%$ dos conselheiros entrevistados vêem como principal dificuldade a desconsideração do Executivo em relação ao poder deliberativo deste fórum. No entanto, os conselheiros se dividem quando questionados se o gestor está ou não disposto a partilhar o poder. Um total de 51,2\% entende que há uma disposição dos gestores em direção ao compartilhamento de poder e 47,6\% avalia que não há tal disposição. Segundo alguns autores $^{13-15}$ :

nesses espaços a deliberação deve ser entendida não apenas como um processo de tomada de decisão, mas também como um processo argumentativo, dialógico, onde os atores fazem propostas e através da comunicação se estabelecem acordos e são formados consensos sobre políticas na área de saúde

Seria oportuno um resgate do significado clássico da política como concebido na polis grega "o significado da política é a liberdade" ${ }^{16}$. Liberdade compreendida não como uma representação das liberdades individuais, mas como autonomia para participarmos da construção de um bem comum. Liberdade enquanto possibilidade de construirmos comunitariamente direitos e deveres através de discussões e persuasões. Liberdade enquanto possibilidade de não acatarmos decisões totalitárias vindas de cima, de nos afastarmos do âmbito da coação.

No entanto um autor clássico nos faz ver que tal conceito de política foi rompido pelos regimes totalitários da era moderna em favor do significado de política como relação de domínio e poder a ponto de justificar inclusive o monopólio do uso legítimo da força pelo Estado ${ }^{17}$.

\section{Resultados e discussão}

Um retrato das resoluções aprovadas no CMS/ BH desde seu inicio até dezembro de 2010 em relação ao registro de homologações pode ser observada na Tabela 1.

No período no qual se propõe aprofundar (1997-2008) 54 das 234 resoluções aprovadas (24\%) não apresentam nenhum registro de homologação ou indeferimento pelos prefeitos.

Avaliando os temas das resoluções sem registro com as respectivas atas construiu-se uma classificação baseada na possibilidade da gestão se posicionar de modo mais ou menos favorável em relação à deliberação. Tal classificação se apresenta nos Quadros 1, 2 e 3.

A Tabela 2 apresenta o percentual de resoluções segundo a classificação proposta.

A análise documental das atas das reuniões em que as resoluções sem registro foram aprovadas mostra que um percentual significativo de resoluções em branco (41\%) coincide com oposições declaradas dos gestores em relação às propostas aprovadas.

Observando os temas das deliberações aprovadas no CMS/BH desde seu inicio fica claro que foi no período 1997-2008 que aconteceram as maiores oposições entre os projetos políticos do Executivo e os dos representantes da democracia participativa no setor da saúde. Quase todas as resoluções com os temas mais polêmicos na história do CMS/BH que está sem registro de homologação ou veto se concentra neste período, assim como a única resolução indeferida pelo Executivo. Outras constatações em relação a este período são apresentadas abaixo:

a) Todas as oito resoluções referentes à realização ou solicitação de auditorias estão neste período. Seis não apresentam registro de homologação ou veto pelo Executivo.

b) Apenas neste período são encontradas resoluções com posicionamento contrário a terceirizações e contratos administrativos, a favor da realização de concursos, pela ampliação do quadro de pessoal e pela nomeação de concursa-

Tabela 1. Situação das resoluções no período entre 1989 e 2010.

\begin{tabular}{cccc}
\hline $\begin{array}{c}\text { Resoluções com registro } \\
\text { de homologação }\end{array}$ & $\begin{array}{c}\text { Resoluções sem registro } \\
\text { de homologação }\end{array}$ & Total \\
\hline $\mathbf{N}=18$ & $\%=74$ & $\mathbf{N}=75 \quad \%=26^{*}$ & $\mathbf{N}=293 \quad \%=100$ \\
\hline
\end{tabular}

*incluída aqui 1 resolução vetada 


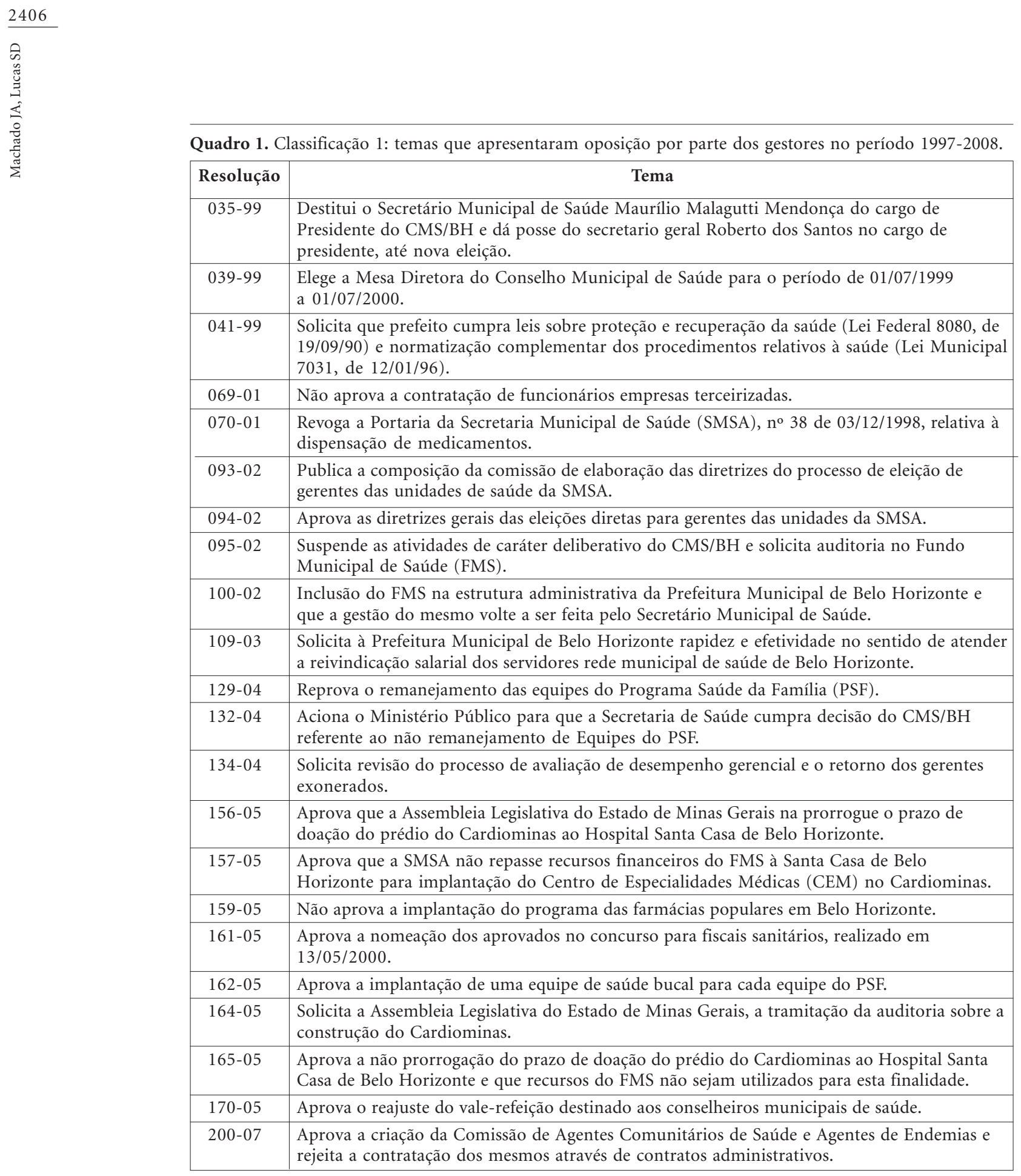

Fonte: Site do CMS/BH

dos, temas que apresentam uma longa história de enfrentamento entre as gestões públicas e a sociedade;

c) Coincide também com este período a aprovação de uma resolução solicitando rapidez e efetividade do Executivo no atendimento da reivindicação salarial dos servidores da saúde. Foi a única vez em que o CMS/BH se posicionou formalmente durante uma campanha salarial; d) Uma incisiva defesa da integralidade do Sistema Único de Saúde também ocorreu nesse período com o veto à implantação das Farmácias Populares no município. O CMS/BH entendeu que tal proposta representava uma quebra da integralidade já que a população deveria pagar pelos medicamentos. Apesar da decisão o Executivo implantou as Farmácias Populares através de outra secretaria, a de Desenvolvimento Social; 
Quadro 2. Classificação 2: temas que não apresentaram oposição dos gestores mas apresentam alta ou significativa possibilidade de discordância dos mesmos no período 1997-2008.

\begin{tabular}{|c|l|}
\hline Resolução & \multicolumn{1}{c|}{ Tema } \\
\hline $068-01$ & Aprova a realização de uma auditoria sobre a questão dos medicamentos na capital. \\
\hline $079-02$ & Aprova a realização de auditoria no Programa Saúde Bucal da SMSA. \\
\hline $098-02$ & Solicita a nomeação dos fiscais sanitários aprovados no concurso de 13/05/2000. \\
\hline $099-02$ & $\begin{array}{l}\text { Resolve que não se faça mais processo licitatório para contratação de trabalhadores por meio } \\
\text { de empresas terceirizadas na área de saúde em Belo Horizonte sem prévia discussão com o } \\
\text { CMS/BH, que a SMSA encaminhe à Câmara Municipal projeto ampliando o quadro da } \\
\text { saúde e que todas as contratações de profissionais da saúde sejam feitas através de concurso } \\
\text { público, exceto nas situações emergenciais conforme texto constitucional. }\end{array}$ \\
\hline $120-03$ & $\begin{array}{l}\text { Aprova a criação de conselhos de saúde nos hospitais públicos e solicita que SMSA faça uma } \\
\text { auditoria financeira e assistencial nos hospitais públicos e filantrópicos da rede SUS/BH. }\end{array}$ \\
\hline $155-05$ & Aprova a realização de auditoria externa na Gerência de Assistência Farmacêutica da SMSA. \\
\hline
\end{tabular}

Fonte: Site do CMS/BH

e) Outro momento de enfrentamento nesse período e cujas resoluções não apresentam registro de homologação se refere à aprovação de diretrizes para a implantação do processo eleitoral para os cargos de gerentes das unidades de saúde. $\mathrm{O}$ único indeferimento de uma resolução pelo Executivo é este. O CMS/BH rejeitou o indeferimento e aprovou novamente a resolução orientando a criação de uma comissão que elaborasse as diretrizes das eleições, mas a mesma não apresenta registro de homologação. Posteriormente, nesse mesmo período, aprovou resolução no sentido de que alguns gerentes exonerados pela Secretaria de Saúde retornassem a seus cargos, que também ficou sem registro de homologação;

f) Um grande debate ocorrido logo após as eleições de gerentes se relacionou à gestão do Fundo Municipal de Saúde - FMS, que deixou de ser gerido pelo Secretário de Saúde. O CMS/BH aprovou resoluções solicitando uma auditoria no FMS, pleiteando que sua gestão voltasse a ser feita pelo Secretário de Saúde e suspendendo as deliberações do Conselho;

g) A única resolução acionando o Ministério Público contra a Secretaria de Saúde também se refere a esse período, após o CMS/BH reprovar um remanejamento de equipes do Programa de Saúde da Família e o Executivo não acatar tal decisão.

Diante de tais observações pode-se constatar que as resoluções do $\mathrm{CMS} / \mathrm{BH}$ que significaram maiores enfrentamentos com o Executivo não foram homologadas, mas também não receberam o carimbo e a assinatura dos prefeitos indeferindo as mesmas. Há a possibilidade de que os prefeitos evitem dessa forma o ônus político que significaria vetar resoluções aprovadas em um fórum deliberativo composto por usuários, trabalhadores, prestadores e gestores do Sistema Único de Saúde, mas isso demanda outro estudo.

Para um estudioso desta temática:

... O Conselho é deliberativo no texto da lei. $\mathrm{Na}$ realidade, as deliberações são pontualmente atendidas quando há convergência de interesses entre a deliberação do Conselho e o gestor. Aí o Conselho tem sua deliberação cumprida. Quando não há, como existe a figura da homologação porque para virar uma ação governamental ela tem que estar inscrita na agenda governamental e a forma é uma portaria que homologa -, simplesmente o gestor senta em cima e essa portaria não vai sair nunca. Ele nem enfrenta o Conselho. Deixa sair a deliberação, mas não homologa ${ }^{18}$.

Apesar das dificuldades de informação em relação às resoluções sem registro, a organização dos dados aqui apresentados proporcionou uma avaliação da dinâmica política do CMS/BH. No capítulo seguinte algumas conclusões fundamentadas nos dados obtidos serão colocadas.

\section{Considerações finais}

O percentual de resoluções homologadas pelos prefeitos desde o início das atividades do CMS/ BH (1989) até o ano de 2010 é de 74\%, ou seja, a grande maioria das resoluções vem sendo homologadas pelos prefeitos. No entanto $26 \%$ do total de resoluções não apresenta nenhum registro de homologação ou veto pelo Executivo. Considerando-se que a homologação das decisões do conselho é um dever do Executivo pode-se 
Quadro 3. Classificação 3: temas que não apresentaram oposição por parte dos gestores, e apresentam baixa ou nenhuma possibilidade de discordância dos mesmos no período 1997-2008

\begin{tabular}{|c|c|}
\hline Resolução & Tema \\
\hline 015-97 & Constitui a Comissão Municipal de Saúde do Trabalhador. \\
\hline 077-01 & Aprova o regulamento do processo de seleção de Agentes Comunitários de Saúde. \\
\hline 087-02 & Confirma a condição de gestão plena do Sistema Municipal de Saúde de Belo Horizonte. \\
\hline 088-02 & Aprova o aumento de $15 \%$ no valor da bolsa de desospitalização psiquiátrica. \\
\hline 097-02 & Aprova pagamento diferenciado para ecocardiograma. \\
\hline $102-02$ & Aprova a Proposta Orçamentária do FMS, para exercício financeiro de 2003. \\
\hline $103-02$ & $\begin{array}{l}\text { Aprova implantação do Centro de Referência em Diabetes e Hipertensão no PAM Padre } \\
\text { Eustáquio. }\end{array}$ \\
\hline $104-02$ & Cria a carteira de identificação para conselheiros municipais de saúde de Belo Horizonte. \\
\hline $110-03$ & Aprova o projeto Conselho na Praça. \\
\hline $111-03$ & Aprova com recomendações o plano de ações e metas DST/AIDS da SMSA, referente a 2003. \\
\hline $112-03$ & Aprova com recomendação a Programação Pactuada Integrada. \\
\hline $113-03$ & $\begin{array}{l}\text { Aprova o Projeto de Expansão e Consolidação da Saúde da Família (PROESF) para Belo } \\
\text { Horizonte. }\end{array}$ \\
\hline $126-04$ & $\begin{array}{l}\text { Altera as Resoluções } 097 / 2002 \text { e } 122 / 2003 \text { em relação a pagamento diferenciado de } \\
\text { ecocardiograma. }\end{array}$ \\
\hline $128-04$ & $\begin{array}{l}\text { Cria uma comissão para acompanhar o processo de internação de paciente na rede hospitalar } \\
\text { pública, privada e filantrópica conveniada ao SUS de Belo Horizonte. }\end{array}$ \\
\hline $131-04$ & Aprova a manutenção da Política de Saúde Mental. \\
\hline $143-04$ & $\begin{array}{l}\text { Aprova o Projeto Amigo do SUS nas unidades básicas de saúde de Belo Horizonte, com } \\
\text { participação conselhos distritais e comissões locais. }\end{array}$ \\
\hline 153-05 & $\begin{array}{l}\text { Aprova que a Secretaria Municipal de Saúde deve fornecer estrutura aos conselhos distritais e } \\
\text { que os funcionários dos conselhos distritais de saúde sejam selecionados pelo respectivo Conselho } \\
\text { Distrital de Saúde e subordinados à Mesa Diretora. }\end{array}$ \\
\hline 158-05 & $\begin{array}{l}\text { Aprova que a Secretaria Municipal de Saúde apresente ao CMS/BH a proposta orçamentária do } \\
\text { Fundo Municipal de Saúde de forma didática. }\end{array}$ \\
\hline $160-05$ & $\begin{array}{l}\text { Aprova que os recursos financeiros federais destinados às ações da Vigilância Sanitária sejam } \\
\text { utilizados para custeio de transporte dos fiscais sanitários de Belo Horizonte. }\end{array}$ \\
\hline $163-05$ & $\begin{array}{l}\text { Aprova a implantação do Projeto Global das Especialidades Médicas e que serviços que não } \\
\text { forem públicos sejam objeto de apreciação e deliberação do CMS/BH. }\end{array}$ \\
\hline 173-05 & $\begin{array}{l}\text { Aprova com ressalvas os Relatórios de Gestão do Fundo Municipal de Saúde e do Hospital } \\
\text { Odilon Behrens, referente ao ano de } 2004 \text {. }\end{array}$ \\
\hline $184-05$ & Aprova o Projeto de Controle Populacional de Cães e Gatos. \\
\hline 199-06 & $\begin{array}{l}\text { Aprova com ressalvas o Plano de Ações e Metas DST/AIDS da Secretaria Municipal de Saúde de } \\
\text { Belo Horizonte. }\end{array}$ \\
\hline $215-07$ & $\begin{array}{l}\text { Aprova com recomendações o projeto Residência Multiprofissional em Saúde do Hospital } \\
\text { Odilon Behrens. }\end{array}$ \\
\hline 247-08 & Aprova com recomendações o Programa Saúde na Escola. \\
\hline $248-08$ & Aprova com recomendações o indicador de controle social. \\
\hline
\end{tabular}

Fonte: Site do CMS/BH

Tabela 2. Percentual de resoluções sem registro segundo a classificação no período 1997-2008

\begin{tabular}{lccc}
\hline & Classificação 1 & Classificação 2 & Classificação 3 \\
\hline Percentual & $41 \%$ & $11 \%$ & $48 \%$ \\
\hline
\end{tabular}

Fonte: Arquivo de Resoluções e Site do CMS/BH. 
dizer que este percentual é bastante significativo. Apesar do volume de resoluções sem homologação, apenas uma vez o CMS/BH deliberou pelo acionamento do Ministério Público.

A hipótese colocada pela Secretaria Executiva de que várias resoluções em branco podem ter sido homologadas pelos prefeitos, mas que não retornaram revela a necessidade de um acompanhamento maior do trâmite das resoluções por parte dos presidentes e das mesas diretoras do $\mathrm{CMS} / \mathrm{BH}$.

O fato de 52\% das resoluções sem registro no período 1997-2008 se referirem a temas que apresentaram oposição por parte da gestão ou alta/ significativa possibilidade de discordância por parte da gestão, e também o fato de apenas uma resolução em toda a história do CMS/BH ter sido indeferida nos sugere que o Executivo não vem assumindo publicamente seus vetos. A quase totalidade das solicitações de auditoria não foi homologada, revelando um recuo da gestão em relação à transparência e à exposição frente à opinião pública. Aqui deve-se considerar que $80 \%$ de todas as resoluções aprovadas no $\mathrm{CMS} / \mathrm{BH}$ correspondem ao intervalo 1997-2008.

Também neste período pode-se observar que $41 \%$ das resoluções sem registro de homologação ou veto coincidem com a classificação 1 , demonstrando que aí se encontram os maiores debates entre os atores deste fórum, consolidando o Conselho Municipal de Saúde de Belo Horizonte como legítimo e pleno espaço de exercício da cidadania e da democracia participativa na cidade.

A partir do contexto apresentado conclui-se que é necessário que os conselheiros estejam mais bem preparados para o enfrentamento dos desafios. Há a necessidade de movimentos no sentido do fortalecimento da cidadania e do capital social nesse espaço, pois a própria existência de um número tão grande de resoluções sem registro nos arquivos demonstra a fragilidade do fórum quando não cobra do Executivo um posicionamento em relação às decisões construídas pelo debate e aprovadas em suas plenárias. A Resolução $n^{\circ} 333^{2}$ apresenta mecanismos para que o Conselho se coloque enquanto uma instância deliberativa na relação com o Executivo, sugerindo inclusive ações junto ao Ministério Público quando os prefeitos não homologam as resoluções. Por que então os conselheiros não recorrem a tais mecanismos? Seria em razão de aspectos históricos da sociedade brasileira como o precário exercício da cidadania, o clientelismo e o patrimonialismo? Outra dúvida: podemos perceber que grande parte dos representantes dos movimentos sociais são filia- dos a partidos políticos. $\mathrm{O}$ atual contexto de alianças pluripartidárias estaria comprometendo as cobranças de representantes do $\mathrm{CMS} / \mathrm{BH}$, que evitariam acionar o Ministério Público devido a comprometimentos político-partidários com o Executivo? A averiguação de tais hipóteses necessita de maiores estudos.

Atualmente Belo Horizonte tem assistido a importantes discussões no campo da participação popular. A Câmara de Vereadores tenta limitar o poder deliberativo dos conselhos de políticas públicas com um projeto que submete à apreciação dos vereadores as decisões mais relevantes. Um vereador chegou a declarar que os conselhos não foram feitos para deliberar, mas para aconselhar, num claro desconhecimento ou mesmo num enfrentamento em relação à legislação federal. Sabemos que processos históricos são construídos a partir de avanços e recuos, mas nos assusta constatar que a Câmara de Vereadores, que legislou em favor da democracia participativa ao definir que o presidente do CMS/ BH não seria mais o secretário de saúde em exercício e sim um representante eleito entre seus membros, se encontre em tamanho retrocesso político 13 anos depois.

$\mathrm{Na}$ atual gestão municipal vem se evidenciando a falta de grandes debates no CMS/BH. Apesar das atas deste período não terem sido estudadas pode-se perceber com clareza, a partir dos temas das resoluções, que o segmento que vem conduzindo a agenda neste fórum de democracia participativa é o governo. Seria interessante uma análise ao final do mandato pois o atual retrocesso político em relação à democracia participativa não vem se localizando apenas no Legislativo. $\mathrm{O}$ prefeito Márcio Lacerda estabeleceu no Decreto 14.639 uma padronização de normas para o funcionamento dos Conselhos Municipais de Políticas Públicas ${ }^{19}$ numa aparente tentativa de centralizar poderes. Em relação às homologações tal decreto estabelece que: Os Conselhos cuja deliberação necessite de homologação do Prefeito deverão, além de publicar as atas de suas reuniões no Sistema de Acompanhamento de Colegiados, enviá-las ao Gabinete do Prefeito, em até 3 (três) dias úteis contados de sua aprovação. No entanto não há no decreto nenhum prazo previsto a ser cumprido pelo Gabinete do Prefeito no retorno das homologações para os Conselhos. Se tal tentativa de organização trouxer maior institucionalidade e transparência dos prefeitos em relação às deliberações até poderá haver algum ganho.

O Relatório Crítico da Controladoria Geral da União $(\mathrm{CGU})^{9}$ apontou a necessidade de se 
estabelecer uma agenda que proponha a regulamentação das atribuições dos conselheiros e dos seus direitos perante o Estado. No contexto atual a demora em se estabelecer tal agenda pode comprometer os avanços que a Frente BH-Popular tentou trazer à democracia da cidade. $\mathrm{O}$ caminho a se seguir para evitar um retrocesso no campo da democracia participativa dependerá da capacidade dos atores deste fórum de fazerem valer suas deliberações.

\section{Colaboradores}

JA Machado e SD Lucas participaram igualmente de todas as etapas de elaboração do artigo. 


\section{Referências}

1. Brasil. Lei no 8.142 de 28 de dezembro de 1990 . Dispõe sobre a participação da comunidade na gestão do Sistema Único de Saúde (SUS) e sobre as transferências intergovernamentais de recursos financeiros na área da saúde e dá outras providências. Diário Oficial da União 1990; $31 \mathrm{dez}$.

2. Brasil. Resolução no 333 de 4 de novembro de 2003. Aprova as diretrizes para criação, reformulação, estruturação e funcionamento dos Conselhos de Saúde. Diário Oficial da União 2003; 4 dez.

3. Brasil. Constituição da República Federativa do Brasil. Diário Oficial da União 1988; 5 out.

4. Brasil. Lei no 8.080 de 19 de setembro de 1990 . Dispõe sobre as condições para promoção, proteção e recuperação da saúde, a organização e o funcionamento dos serviços correspondentes, e dá outras providências. Diário Oficial da União 1990. 20 set.

5. Lyra RP. Democracia Representativa x Democracia Participativa: a representação do Estado e da sociedade civil nos conselhos de políticas públicas. In: Anais do II Seminário Nacional Movimentos Sociais, Participação e Democracia; 2007; Florianópolis. p. 602-628.

6. Van Stralen CJ, Lima AMD, Fonseca Sobrinho D, Saraiva LES, Van Stralen TBS, Belisário SA. Conselhos de Saúde: efetividade do controle social em municípios de Goiás e Mato Grosso do Sul. Cien Saude Colet 2006; 15(3):621-632.

7. Avritzer L. Instituições participativas e desenho institucional: algumas considerações sobre a variação da participação no Brasil democrático. Opinião Pública 2008; 14(1):43-64.

8. Langosky DT. Estado, democracia participativa e empoderamento. Revista Jus Vigilantibus. [periódico na Internet]. 2008 ago [acessado 2011 out 14]. Disponível em: http://jusvi.com/artigos/35677

9. Brasil. Controladoria Geral da União (CGU). A sociedade no acompanhamento da gestão pública. In: Controladoria Geral da União (CGU). Relatório Crítico do I Seminário Nacional de Controle Social. Brasília: CGU; 2009.

10. Putnam RD. Comunidade e democracia: a experiência da Itália moderna. 4a Edição. Rio de Janeiro: Editora FGV; 2005.
11. Hernandez OD. Participación y construcción de la subjetividad social para uma proyección emancipatoria. $1^{\text {a }}$ Edición. La Habana: Publicaciones Acuario; 2005.

12. Raczynski D. Equidad, inversion social y pobreza; innovar in como se concibe, diseña y gestiona la políticas y los programas sociales. Cepal [Internet] 2001. [acessado 2011 out 14] Disponível em: http:/ /www.cepal.org/noticias/discursos/0/10250/ Raczynski.pdf

13. Avritzer L, Cunha ESM, Mota AC, Jardim LS, Quiroga I, Passos J. Relatório de Pesquisa apresentado à FAPEMIG como resultado do projeto: Reinventando os mecanismos de inclusão e controle social nos conselhos de saúde. Belo Horizonte: UFMG; 2005.

14. Cunha ESM. Aprofundando a democracia: o potencial dos conselhos de políticas e orçamentos participativos [dissertação]. Belo Horizonte: Universidade Federal de Minas Gerais; 2004.

15. Coelho VSP, Nobre M. Participação e deliberação: teoria democrática e experiências institucionais no Brasil contemporâneo. 1a Edição. São Paulo: Ed. 34; 2004.

16. Arendt H. A promessa da política. Kohn J, organizador. Rio de Janeiro: Difel; 2008.

17. Bobbio N. Teoria geral da política: a filosofia política e as lições dos clássicos. São Paulo: Campus, Elsevier; 2000.

18. Teixeira ACC, organizador. Os sentidos da democracia e da participação. São Paulo: Instituto Polis; 2005.

19. Belo Horizonte. Decreto no 14.639 de 10 nov. 2011. Institui normas gerais mínimas de funcionamento para os Conselhos Municipais de Políticas Públicas de Belo Horizonte. Diário Oficial do Município 2011; 11 nov.

Artigo apresentado em 02/08/2012

Aprovado em 15/11/2012

Versão final apresentada em 30/11/2012 
